HUOM! Tämä on alkuperäisen artikkelin rinnakkaistallenne. Rinnakkaistallenne saattaa erota alkuperäisestä sivutukseltaan ja painoasultaan.

Käytä viittauksessa alkuperäistä lähdettä:

A. Nikina-Ruohonen, S. Heiniö (2021) RE-IMAGINING STUDENTS' MASTER THESIS GUIDANCE IN THE VIRTUAL LEARNING ENVIRONMENT, INTED2021 Proceedings, pp. 9705-9711. https://doi.org/10.21125/inted.2021.2025

PLEASE NOTE! This in an electronic self-archived version of the original article. This reprint may differ from the original in pagination and typographic detail.

Please cite the original version:

A. Nikina-Ruohonen, S. Heiniö (2021) RE-IMAGINING STUDENTS' MASTER THESIS GUIDANCE IN THE VIRTUAL LEARNING ENVIRONMENT, INTED2021 Proceedings, pp. 9705-9711.

https://doi.org/10.21125/inted.2021.2025

(C) 2021 IATED 


\title{
RE-IMAGINING STUDENTS' MASTER THESIS GUIDANCE IN THE VIRTUAL LEARNING ENVIRONMENT
}

\author{
Anna Nikina-Ruohonen ${ }^{1}$, Sanna Heiniö2 \\ ${ }^{1}$ Researcher, Haaga-Helia University of Applied Sciences, Helsinki (FINLAND) \\ ${ }^{2}$ Higher Education Specialist, Master Degree Program, Haaga-Helia University of Applied \\ Sciences, Helsinki (FINLAND)
}

\begin{abstract}
Throughout times students' thesis guidance has largely remained in its traditional, conservative, unchanged form in respect to content, evaluation and approach. Covid-19 has resulted in all forms of teaching and learning being reviewed, and this has pushed for thesis guidance to be adapted and revised. Following the action research approach, the authors planned and implemented a novel pedagogical method of student guidance during their Master's theses writing in the virtual learning environment. With the overall sample size of 23 students, the experiment included four student groups, two of which were led in English and two in Finnish languages, over the course of three to four months each. The students were in the master degree program of a Finnish higher education institute, came from various backgrounds, with multiple cultural and professional reference points. The aim of the project was to test and conceptualize a new approach that better serves (1) students' engagement and project management skills, (2) helps to achieve results short-term, and (3) offers sufficient sense of well-being and support in virtual setting. The results of the experiment were tangible and excellent, as demonstrated by significantly reduced time in completing a Master's thesis as well as student feedback and students' factual progress in their thesis writing.
\end{abstract}

As an outcome, the authors propose and conceptualize the developed and tested pedagogical method of the "Master Thesis Train", especially adapted to the environment of virtual guidance, where students receive relevant content, support and structure to complete the thesis process effectively. The "Master Thesis Train" concept is built around targeted group guidance and personal guidance both of which ran side-by-side with the student's actual advancement of the thesis project, with personalized and clear deliverables.

The implications of the novel pedagogical method "Master Thesis Train" are numerous. First, the research makes it possible to reinvent the approach to students' thesis guidance and align it with the contemporary needs of students for balancing their work and life priorities with those of thesis writing. From the student perspective, reinventing the approach to thesis guidance opens up more space for their own experimentation of new research and thesis writing methods - more diverse and flexible. Second, the "Master Thesis Train" highlights and brings to the front stage the influence of the group interaction as a part of what is traditionally viewed as isolated and independent process of writing a Master's thesis. Third, the high-quality steering process expands the boundaries of a professor and thesis supervisor to the roles of a virtual personal trainer and supporter. Fourth, higher education institutions benefit from the application of the "Master Thesis Train" in terms of such institutional outcomes as resource efficiency and reduced time of students in completing their theses and graduating. Fifth, "Master Thesis Train" was carried out during May-November 2020, in the midst of the Covid-19 outbreak, and was designed to address the challenge of effective and result-oriented thesis guidance fully carried out in the virtual environment. Due to the excellent received outcomes in testing the pedagogical innovation, there is strong evidence that "Master Thesis Train" may be successfully replicated and remain in the permanent toolkit for students' Master's thesis guidance in higher education institutions internationally.

Keywords: student guidance, virtual guidance, virtual communities of practice, pedagogical innovation, higher education.

\section{INTRODUCTION}

In completing a Master's degree, the Master's thesis is the victory flag placed at the mountain top. However, the journey to the top of the mountain is paved with many challenges and uncertainties: How to get started? Is my topic interesting enough? What is really required of me? How long will this 
take me and how hard will it be? Can I do this alone? As a result, many students delay their thesis writing, struggle with it or in the worse-case scenario forego completing it altogether.

Adding to the challenge, the year 2020 transformed the world of education, the outbreak of Covid-19 resulted in all forms of teaching and learning being reviewed, pushing also for thesis guidance to be adapted and revised. Following this call, the authors have designed, implemented and successfully tested the new pedagogical approach to Master's thesis guidance - "Master Thesis Train", which combines individual and group guidance, adapted to the virtual environment. Instead of walking alone towards completing a Master's thesis, students were invited to hop on the "Master Thesis Train" and make the journey towards the mountain top together with a small group of like-minded peers and the tutor in the role of a virtual trainer and supporter.

\section{LITERATURE REVIEW}

The authors applied socio-constructivist counselling literature, model of intrinsic motivation, and explored the idea of virtual communities of practice in the context of thesis guidance.

The digital connectivist approach to learning offers the grounds for fostering social interactions connected through the online technologies, supporting collaborative epistemology in which learning is facilitated, amplified and created [1] [2]. Traditional Master's thesis guidance is often topic-oriented, where a thesis advisor has a powerful position in holding subject expertise and a student is in the role of a novice learner. This is counterintuitive and outdated in relation to the premises of the constructivist counselling, where students would be viewed as "self-organizing" systems rather than information processors or sets of traits. The approach is supported by the calls for learning that accentuates critical thinking and problem solving [3] within the social connectivist paradigm and as advanced by Peavy, Siemens and earlier Vygotskyian views. The role of the counsellor - and in this case thesis advisor - is shaped accordingly to facilitate students' self-organization, meaning-making and self-expansion.

The quality of the advisor-student relationship forms the basis for the successful thesis completion [4]. Facilitated support and interaction lead to a student's reflection, critical thinking, while at the same time building up his/her feeling of confidence. This prevents the relational imbalance between a thesis advisor and a student, enabling open, fluent and timely exchange of information and cooperation.

The shift towards the online learning environment has boosted the research efforts that expand the understanding of virtual communities of practice, with the community of practice defined as members of a community, who are informally bound by what they do together [5]. Recently, the special emphasis has been placed on understanding the interpersonal behaviour, group dynamics and emotional experiences on the intersection of virtuality and emotions [6]. This offers potentially valuable insight for developing virtual communities of practice, such as "Master Thesis Train" among graduate students. As one of the examples, students have been noted to report an emotional barrier and a feeling of stress when deciding whether to reach out to their thesis advisor or not: students are aware that their advisors also have teaching, research, administrative responsibilities and other duties to take care of. Feeling inadequate "I haven't improved very much, my text is not really good yet, I do not want to take up her/his time". In contrast, "Master Thesis Train" meetings are planned and scheduled for everyone to join in, despite the quantity or the quality of the writing done between the meetings.

Here, the role of the advisor leading "Master Thesis Train" is yet again reinforced. Hattie [7] studied the impact of quality of teaching on learning outcomes, discovering that a teacher adopting the mindset of an "activator" has a significant impact on how students achieve results by leading the reciprocal effect in groups, giving feedback, challenging the students.

Students' motivation, readiness to produce results and move their research forward is highlighted by the fact that graduate research was found to have a psychological component to it [8]. Based on the constructivist approach, it is essential that a student forms the internal motivation to complete the course. The Master's thesis is the most demanding part of the degree and students are left quite alone with an extensive research and development task that they often have no prior experience with. Everything might seem confusing, and it is difficult to identify the different steps in the process.

In the traditional approach to thesis supervision it is the thesis advisor who primarily gives feedback and participates in the thesis journey with the student. A high number of students do not meet the timeframe associated with the thesis writing, and this was found to be attributed to the lack of experience in students or inefficient supervision [9] [10]. Since thesis is a personal study without 
definite right and wrong perspectives and ideas, students would benefit from a more multivocal and diverse group and feedback. Also seeing and hearing other students' presentations and reflections often supports the progress of students own thinking and writing.

Research shows that in the work environment setting the main motivations to participate in a group guidance are receiving peer support and learning from others [11]. Similarly, the authors advance that in the context of the graduate-level thesis guidance the motivation and self-efficacy are enhanced by identifying and discussing similar challenges and sharing the experiences connected with thesis writing. Knowledge exists in human interaction [12], the learning depends on the social context, and through interaction between the individual and the community, communal knowledge and skills are conveyed to the individual. As a result, "Master Thesis Train" as a pedagogical approach nourishes the thesis work as a learning process instead of being merely a performance target worth a certain amount of course credits and a ticked boxed on the path towards graduation.

\section{METHODOLOGY}

Developing and testing a novel pedagogical method was central to the present research. The authors planned and implemented a novel pedagogical method of student guidance during their Master's thesis writing in the virtual learning environment. Due to its experimenting nature, the research was exploratory. Therefore, the research followed qualitative methodology, which allowed the access to subjective, lived experiences of the research subjects.

The research focused on a small sample via discretionary selection. With the overall sample size of 23 students, the research included four student groups, two of which were led in English and two in Finnish languages, over the course of three to four months each. The research took place during MayNovember 2020. The students were in a master degree program of a Finnish higher education institute, came from various backgrounds, with multiple cultural and professional reference points.

A combination of judgement and volunteer sampling was applied. The opportunity to take part in "Master Thesis Train" was offered especially to the student pool of those notably lagging behind in or struggling to progress with their Master's thesis writing, which emphasized the need for notable progress and results for each of the students. Thereafter, the interested students from this pool volunteered to take part and signed up for the program.

As qualitative research approach, action research was selected allowing the researchers and participants collaboratively experience, live through, adjust and reflect on the process of Master's thesis writing as carried out in the "Master Thesis Train". The action research as an approach allowed the construction of a shared experience and its joint analysis.

The employed research method was surveys in the form of distributed questionnaires with openended questions - this served as the main source of the collected data. The questionnaires were anonymous and respective languages of the questionnaires and their answers were English and Finnish. The method was selected for how it allowed the students to pause, reflect and focus on the process and outcomes of their experience. The main data was supported with selected numerical evaluation parameters as a part of the distributed questionnaires, observations of the students' factual progress in writing their Master's theses (documented record of what the researchers saw, heard and encountered in the process of supervision), and focus group method, when students' feedback was gathered in the group setting by asking questions and generating discussion.

The data saturation point was reached after the first two out of four student groups completed the "Master Thesis Train" - one in English and the other one in Finnish. While little new information or themes were observed in the subsequent data gathering, the research carried out among the remaining two groups reinforced the initial discoveries and was used to probe for additional details, personal examples and stories.

Data gathering and analysis focused on three dimensions: students' main accomplished progress points with thesis writing during "Master Thesis Train", probing what worked especially well and was experienced as rewarding in the course of the "Master Thesis Train", and understanding what needed to be done differently for the pedagogical method to be more effective.

Within the experiment, the second author introduced the idea of group guidance for a Master's thesis, led the process of sampling, made student observations especially in respect to their progress, coordinated the work with concerned parties of the institute, took part in the data analysis. The first author developed the concept of the Master's thesis guidance as a systematic combination of 
individual and group guidance methods, designed the content for the "Master Thesis Train", led the groups and each of the students throughout the program, created the survey questionnaire together with the second author, carried out the survey, gathered and analyzed results.

The credibility of the research was secured by a systematic approach to planning and carrying out data collection, and consistency in analyses and interpretations, with both authors having vast handson experience in the research field.

\section{RESULTS}

In the course of the research, Master's thesis guidance was reviewed for the virtual environment, with the introduction of "Master Thesis Train" pedagogical approach and concept. Following the testing and conceptualization of "Master Thesis Train", it was noted that the new approach that better serves (1) students' engagement and project management skills, (2) helps to achieve results short-term, and (3) offers additional sense of well-being and support in virtual setting. The results of the experiment demonstrated significantly reduced time in completing a Master's thesis as well as student feedback and students' factual progress in their thesis writing.

\subsection{Conceptualizing Master's thesis guidance for the virtual environment}

Getting students through the process of writing and completing their Master's theses is a challenge both a personal challenge for each of the students and an institutional one in supporting students' timely graduation. In 2020, the challenge was suddenly increased with the outbreak of Covid-19 and the respective necessity to adapt all education activities - Master's thesis guidance included - to the virtual environment. The concept of "Master Thesis Train", as a novel pedagogical approach, was developed translating the challenge into an opportunity to re-imagine effective guidance and support of students' Master's thesis process.

The developed and successfully tested pedagogical approach "Master Thesis Train" was built around targeted small group guidance and personal guidance - both of which ran side-by-side with the students' tangible advancement of the thesis project, personalized and clear deliverables. In this manner, across the period of three to four months, every other week was dedicated to meeting as a group, and every other week was reserved for individual guidance.

Every group meeting had a specific topic, focusing on the key elements of the thesis writing process, such as literature review, research methodology, presentation of results, and other. In a condensed format, the tutor would introduce the basics of sessions theme, combined with the requirements set by the institution. This proved valuable to all of the students, for whom the elements of thesis writing were covered in the past in the connection with the course offering, but were no longer fresh in mind. The results of the survey support this with multiple students having highlighted the progress with the specific parts of the thesis report: "The subject has sharpened for me and became clear", "Thesis structure and contents were completed with Anna's [the tutor] help", "I have defined the scope of my topic, reviewed my research plan and improved it, and I have more knowledge now how to make the analysis of my findings". As one of the students summarized it:

"I was able to outline my topic and finally started my writing work, which has been a really big effort. I have understood what is being sought from me and expected with the thesis and what I need to do to get the job done."

The group meetings would conclude with individual thesis presentations and the respective peer feedback.

"Master Thesis Train" was especially adapted to the environment of virtual guidance, where students receive relevant content, support and structure to complete the thesis process effectively. All of the meetings - both group and individual - took place online and were delivered via Teams-application. Several students pointed out that "Remotely, with the use of Teams-application the thesis guidance works best".

The virtual environment has certain limitations lacking the in-person interaction of the physical world. This requires for the tutor to adapt his or her guidance to the situation. One essential component was to pay extra attention to the verbal and non-verbal clues related to the students' mindset, feelings, progress. Another element was to bring the inspiration and energy to each of the sessions, in addition to knowledge and skills. As some of the best parts of the program, the students highlighted the tutor's 
"concrete know-how, clear instructions on what to do" and "incredible support and expertise", stating that the tutor's "energy is contagious!"

As a result, "Master Thesis Train" program as a whole and its implementation in the virtual environment vividly demonstrated and called for the evolution from a more traditional role of a thesis advisor towards the role of a virtual trainer and supporter.

\subsection{Empowering students' individual work-life and thesis writing balance}

In developing "Master Thesis Train" as a concept, the student-centred approach was adapted and reflected in all of the planning and execution. As one of the aspects, the specifics of master-level students were considered: these are in most cases working adults, balancing their thesis writing with both work and family responsibilities. Therefore, "Master Thesis Train" was delivered on Saturdays, with the possibility for additional individual guidance during evenings on the weekdays. Overall, this was a welcomed and efficient approach for the students:

[There should be] "more of the "Master Thesis Trains" carried out by Anna [tutor] to support students [...]. Easier for a student when you can arrange Teams-meetings remotely and when the Train sessions took place on weekends and you can still get personal meetings on weeknights, when necessary."

In order to offer the necessary guidance and support, it was necessary to understand that in order for the students to progress in thesis writing they had to make it a part of their routine and daily lives. "Master Thesis Train" helped to achieve this, bringing the thesis to the inner circle of life priorities for the needed period of time in order to make the needed push and progress towards the finish line:

"The thesis train and discussions with Anna [tutor] helped me to get on the right track and make progress every week."

Interestingly, "Master Thesis Train" made it possible to consider the individual needs and progress, while at the same time moving the group of students together as a whole. As an outcome, each of the students progressed at their own pace and independently, but in the end all of the students, who completed the program, felt that they made progress:

"The progress of thesis was scheduled to fit the working schedule and I was not able to accomplish it on time, however, the quality of my work increased dramatically as I got to know expectations for this work."

"Concrete progress of the thesis at a steady pace."

Being a part of a group in the thesis writing process empowered students, brought more discipline to the process and made them feel that they were not alone in their struggles - positively contributing to the feelings of psychological comfort and well-being. As one of the students pointed out, "it was nice to have a group of students with whom we discussed topics as well and hear about their experiences".

\subsection{Supporting short-term delivery of Master's thesis results}

The process of writing a Master's thesis is systematic work towards the ultimate results of finishing the thesis report and graduating. In this respect, "Master Thesis Train" met and excelled the expectations. Many of the students, who took part in the program, achieved major progress, with three students submitting their theses for the evaluation immediately after the Train and several more with the plan to do so within the scope of one to six months. The students reflected:

"I started almost from nothing, got immense help regarding everything necessary: received guidance to find relevant research topics, created structure of thesis document, planned research design, even made the first round of thematic interviews."

[My accomplishments were] "finishing the thesis, graduating and receiving the degree diploma."

At the same time, even if the students did not cross the finish line immediately in the course of "Master Thesis Train", their achievements were of a different nature, but equally valuable. In their self-analysis some of the students noted their steady and specific progress in respect to certain parts of the thesis report, for example, having clarified the content and structure, written literature review with the appropriate use of sources, improved their research methodology. 
Often the most difficult step is the first one. The results of "Master Thesis Train" indicate that for the students, who have been postponing thesis writing for months or even years, this was a valuable push and support to start the writing and to gain confidence to overcome that first barrier. The students have commented on their progress: "I now have a topic for my thesis", "I have found the subject", "I have the next steps planned", and furthermore: "The work has got off to a solid start. I now have the skills to finish the thesis with quality".

With the consideration of the individual situation of each of the students, who hopped on the "Master Thesis Train", there was notable advancement of the thesis writing journey. The concrete milestones and results were achieved on three levels: for students individually, for the group, and ultimately for the institution in supporting the students on the road towards graduation.

\section{CONCLUSIONS}

The implications of the novel pedagogical method "Master Thesis Train" are numerous.

First, the research makes it possible to reinvent the approach to students' thesis guidance and align it with the contemporary needs of students for balancing their work and life priorities with those of thesis writing. From the student perspective, reinventing the approach to thesis guidance opens up more space for their own experimentation of new research and thesis writing methods - more diverse and flexible.

Second, the "Master Thesis Train" highlights and brings to front stage the influence of group interaction as a part of what is traditionally viewed as isolated and independent process of writing a Master's thesis.

Third, the high-quality steering process expands the boundaries of a professor and thesis supervisor to the roles of a virtual personal trainer and supporter.

Fourth, higher education institutions benefit from the application of the "Master Thesis Train" in terms of such institutional outcomes as resource efficiency and reduced time of students in completing their theses and graduating.

Fifth, "Master Thesis Train" was carried out during May-November 2020, in the midst of the Covid-19 outbreak, and was designed to address the challenge of effective and result-oriented thesis guidance carried out in full in the virtual environment.

The students, who took part in the program, came from various cultural reference points and diverse professional settings, suggesting that "Master Thesis Train" may be successfully applicable in various contexts. This offers potential for further research and concept testing. Potential insight may be gained from implementing "Master Thesis Train" within various student groups across international and other variables.

Due to the excellent received outcomes in testing the pedagogical innovation, there is strong evidence that "Master Thesis Train" may be successfully replicated and remain in the permanent toolkit for Master's thesis guidance in higher education institutions internationally.

\section{REFERENCES}

[1] G. Siemens, "Connectivism: A Learning Theory for the Digital Age", Journal of Instructional Technology and Distance Learning, vol. 2, no. 1, 2004.

[2] G. Siemens, "Connectivism: Learning Theory or Pastime of the Self-amused", 2006. Retrieved on 25 May 2013 from: http://www.elearnspace.org/Articles/connectivism_self-amused.htm

[3] C. Trilling, B. \& Fadel, 21st Century Skills: Learning for Life in Our Times, San Francisco, CA: Jossey-Bass, 2009.

[4] B. Seagram, J. Gould, and S. Pyke, "An Investigation of Gender and Other Variables on Time to Completion of Doctoral Degrees", Research in Higher Education, vol. 39, no. 3, pp. 319-335.

[5] E. Wenger, R. McDermott, W. Snyder, Communities of Practice: A Guide to Managing Knowledge, Boston, Mass: Harvard Business Review Press, 2002.

[6] A. Behal, "Leading and Managing Virtual Communities of Practice", The Journal - Contemporary Management Research, vol. 13, no. 2, pp. 15 - 37, 2019. 
[7] J. A.C. Hattie, Visible Learning: A Synthesis of Over 800 Meta-analyses Relating to Achievement, New York, NY: Routledge, 2009.

[8] E. M. Phillips and D. S. Pugh, How to Get a PhD- A Handbook for Students and Their Supervisors, Buckingham: Open University Press, 2000.

[9] J. Mouton, How to Succeed in Your Master's and Doctoral Studies, Pretoria: Van Schaik, 2001.

[10] G. Rademeyer, "Thesis Supervision: Getting the Genie Out of the Lamp", South African Journal of Higher Education, vol. 8, no. 2, pp. 92-95, 1994.

[11] S. Tiittinen, E. Weiste, S.Vehviläinen, J. Ruusuvuori, S. Lusa and J. Laitinen, "Reflection Avoidance, and Peer Support", Journal of Adult Education (in Finnish), vol. 3/2018, pp. 208-222, 2018.

[12] R. Säljö, Learning Practices. Sociocultural Perspective, Helsinki: WSOY, 2001. 